\title{
Questão urbana e envelhecimento populacional: breves conexões entre o direito à cidade e o idoso no mercado de trabalho
}

\author{
The urban question and population aging: brief connections \\ between the right to the city and the elderly in the labor market
}

Maura Pardini Bicudo Véras

Jorge Felix

\section{Resumo}

Este texto discute a questão urbana em sua relação com o envelhecimento populacional. De forma resumida, evidencia-se o efeito do capital financeiro, nos séculos XX e XXI, sobre o espaço urbano, o trabalho e a seguridade social. Defende-se que a perda do direito à cidade é o último estágio do desmonte do Estado de Bem-Estar Social. Com o avanço do capital imobiliário, amplia-se a segregação dos moradores, e os mais pobres se alojam em condições precárias nas cidades, onde vivem $84 \%$ dos idosos brasileiros. Esse processo contribui, assim, para a construção de um discurso paradoxal sobre a veIhice, sobretudo, no que diz respeito ao direito ao trabalho e à postergação da aposentadoria diante da maior longevidade. Produz-se hipótese a ser explorada em pesquisa posterior sobre o papel do ambiente construído na decisão de aposentadoria.

Palavras-chave: questão urbana; desenvolvimento econômico; envelhecimento populacional; mercado de trabalho; previdência social.

\begin{abstract}
In this paper, we discuss the urban question and its relation to population aging. We show, in a summarized way, the effect of financial capital, in the 20th and 21st centuries, on urban space, labor and social security. We argue that the loss of the right to the city is the last stage of the dismantling of the Welfare State. With the advance of the real estate capital, the segregation of residents increases, and the poorest ones settle in precarious conditions in the cities, where $84 \%$ of Brazilian elders live. Thus, this process contributes to the construction of a paradoxical discourse about old age, especially with regard to the right to work and the postponement of retirement due to increased longevity. We have produced a hypothesis to be explored in further research regarding the role of the built environment in the decision about retirement.

Keywords: urban question; economic development; population aging; labor market; social security.
\end{abstract}




\section{Introdução}

Na análise da pós-modernidade, dois fenômenos saltam como protagonistas para o entendimento da dinâmica capitalista contemporânea: o processo acelerado de urbanização e o também acelerado processo de envelhecimento da população. Do ponto de vista socioeconômico, esses temas se apresentam dialeticamente relacionados ao avanço do capital financeiro, hipertrofia da sociedade de consumo, individualismo, insegurança pública, efeitos da mundialização ${ }^{1}$ e do liberalismo; além disso, os tempos atuais carregam significados ligados à valorização da liberdade, da construção da identidade, assim como de questões de gênero e etnia, entre outros tópicos caros aos analistas da sociedade dos séculos XX e XXI. Do ponto de vista do aumento da população em cidades brasileiras, essa proporção chegava a $84 \%$ em 2010 e foi estimada em 86\% em 2015 (IBGE, 2011; Ipea, 2014). De 1991 a 2011, a expectativa de vida do brasileiro ampliou-se em 9 anos, saltando de 66,9 para 74,1 anos e, atualmente, $84 \%$ da população com mais de 60 anos vive nas áreas urbanas (IBGE, 2011). ${ }^{2}$

No caso das cidades sob o impacto do neoliberalismo nessa primeira década do século XXI, pode-se questionar e constatar as formas pelas quais se persevera a desigualdade social, mesmo quando ocorrem substanciais progressos econômicos e apesar de algumas ferramentas de proteção social. A desigualdade urbana é estável, resistente, mesmo que mutante. Acompanham tais contrastes sociais, o esvaziamento do espaço público; a proliferação de moradias precárias; a autossegregação das elites, quer nos condomínios fechados, quer nos bairros de melhor qualidade urbana; o espraiamento da pobreza para zonas periféricas, com deficiência de serviços e equipamentos, em combinação perversa de fatores ligados à concentração de renda e da propriedade do solo com ingredientes ligados simbolicamente a cor/etnia, origem e práticas culturais, pois incluem-se valores, hábitos, costumes e significados de todo um fazer humano com suas expressões individuais e distinções sociais.

Pode-se dizer, assim, que a cidade contemporânea não apenas reflete as desigualdades geradas em outras esferas, como, por exemplo, a distribuição de renda, mas que ela mesma é produtora de desigualdades. Nesse sentido, o direito à cidade e ao lugar, como espaço identitário, é o que lhe possibilita aos indivíduos ser mais ou menos cidadão e lhe permite 0 acesso a direitos e à participação política (Santos, 1987). Como nos diz Harvey (2012), a cidade capitalista global, sustentada pelos fortes pilares do livre mercado, transformou-se em um bem de consumo, e seus habitantes vivem dependendo de sua capacidade de consumir o que a cidade lhes oferece. Nesse cenário, insere-se a questão do envelhecimento.

0 envelhecer nas grandes cidades tem sido um objeto de pesquisa cada vez mais presente na Sociologia e outras áreas. 0 interesse crescente no tema surgiu, entre outros marcos, a partir do documento da Organização Mundial de Saúde, publicado em 2008, "Cidade Amiga do Idoso" (OMS, 2008). Desde então, as áreas de economia, urbanismo, direito, sociologia, saúde e gerontologia voltaram-se ao tema seja para avaliar a execução de políticas públicas destinadas a atender às recomendações da OMS em busca do bom 
envelhecimento, seja para fazer conexões entre essas recomendações e a realidade proporcionada pela configuração da economia no século XXI. Por exemplo, no direito à moradia. É o caso de Rolnik, quando destaca que o aumento da propriedade privada da moradia, vis à vis os modelos de moradia social do pós-Segunda Guerra Mundial, e a mobilização crescente desse patrimônio imobiliário como forma de riqueza "coincidem com o processo de envelhecimento da população e com a enorme pressão que isso representou para os sistemas públicos de aposentadoria". A casa própria, destaca a autora, transformou-se em um estoque de riqueza para a vida mais longa devido à aposta em sua valorização ao longo do tempo, que acaba sendo efetivada pela ampliação da especulação imobiliária, e, na prática, termina por substituir os sistemas públicos de previdência (Rolnik, 2015, p. 38).

A intenção aqui é estabelecer relações entre a dinâmica demográfica, o "uso do ambiente construído", no dizer de Harvey (1982), e o discurso econômico defensor da postergação da aposentadoria como um impositivo para uma suposta necessidade de dar sustentação ao sistema de previdência social público (e por repartição). A questão previdenciária em si - quanto ao equilíbrio orçamentário do sistema - está fora do âmbito deste texto, estando presente apenas no bojo do que se entende como Estado do Bem-Estar Social. ${ }^{3}$ É válido, porém, destacar a existência de profícua literatura sobre o componente político e ideológico na análise de seu financiamento dentro de cada concepção de Estado. ${ }^{4}$
0 objetivo é analisar, portanto, como 0 movimento do capital financeiro, em forma de sua fração imobiliária, interfere na construção do espaço urbano de maneira que limita as possibilidades do viver do trabalhador idoso (60 anos ou mais) nas grandes cidades. ${ }^{5} \mathrm{~A}$ hipótese a ser discutida é como essa "construção" corrobora para a decisão de antecipação da aposentadoria e desmistifica o discurso de uma possibilidade universal, diante da maior longevidade, de uma reinvenção do trabalhador na fase pós-laboral, por meio de uma segunda carreira profissional. Esses dois pontos (postergação da aposentadoria e nova carreira) foram selecionados por sua relevância no debate econômico internacional sobre o fenômeno do envelhecimento da população, estabelecido sobretudo na defesa da adoção de idade mínima para a elegibilidade aos sistemas de aposentadoria.

Na próxima seção será feita uma exposição breve do desmonte do Estado do Bem-Estar Social a partir do fim dos anos 1970 e, sobretudo, depois da crise financeira de 2007/2008. Em seguida, serão relatadas a construção de uma nova velhice na pós-modernidade e o uso desta representação no discurso da economia mainstream ${ }^{6}$ em relação ao mundo do trabalho e à aposentadoria. Na quarta seção, será analisado como o avanço do capital financeiro constrói o ambiente à sua mercê e em detrimento da "classe-que-vive-do-trabalho" (Antunes, 2011). Na última seção, à guisa de considerações finais, será discutida a dissonância cognitiva do discurso econômico neoliberal sobre o alongamento da vida laboral com a realidade imposta pela questão urbana. 


\section{A construção do Estado do 'Mal-Estar Social'}

No entender de Oliveira (2004), a América Latina jamais conheceu um Estado do Bem-Estar Social como este se apresentou aos europeus no pós Segunda Guerra Mundial, seja qual for o modelo usado como referência (continental, anglo-saxão ou escandinavo). ${ }^{7}$ De acordo com o autor, o caso latino-americano sempre se pareceu mais com o "Estado do Mal-Estar Social". Mesmo com essa assimetria, acentuada a partir da década de 1970, com a fase chamada de "reestruturação do capital", a América Latina sofre igualmente, ao lado da Europa, com o desmonte da proteção social erguida desde o século XIX por Otto von Bismark (1815-1898) e ampliada no pós-guerra.

Tanto em um continente quanto no outro, esse processo se agrava na década de 1990 e radicaliza-se após a crise financeira de 2007/2008 com a política de austeridade fiscal, especificamente na questão de Previdência Social. Enquanto, na Europa, vários países promoveram reformas e elevação da idade mínima para a aposentadoria, no Brasil, completou-se a reforma de 2003 com a aprovação da lei que cria os fundos de pensão para os funcionários públicos (Lei n. 12.618/2012) e alteraram-se, mais uma vez, as regras do Regime Geral de Previdência (Lei n. 13.183/2015), com adoção de alternativas ao fator previdenciário para o contribuinte aposentado por tempo de contribuição.

0 que é relevante destacar, neste artigo, é aquela rede de proteção construída no pós-guerra que cruzava as fronteiras de seguro desemprego, assistência social, previdência e sistemas de saúde, e que, de forma amplia$\mathrm{da}$, pode ser detectada em serviços sociais que dizem respeito à educação, moradia, arte, cultura, aparelhos para recreação situados em subúrbios, transportes públicos subsidiados e até mesmo nos subsídios agrícolas (Judt, 2007, p. 87). Ou seja, participava da construção do ambiente rural e urbano. 0 chamado Welfare State - dispensável despender energia aqui para defini-lo em detalhes - foi, portanto, um conceito amplo na busca do bem-estar, com voluntarismo do Estado, e resultou em um amortecedor na relação entre o capital e o trabalho, acomodando a principal contradição capitalista em uma sociedade dita salarial (Castel, 2012, p. 463).

Bauman lembra ainda que o estado de bem-estar social foi concebido a fim de reabilitar os temporariamente inaptos e estimular os que estavam aptos a se empenharem ainda mais (1998, p. 51). Longe de ser caridade, sublinha o autor, era um direito [grifo dele] do cidadão e não o fornecimento de donativos individuais. Era uma forma de seguro coletivo. Ainda válido destacar, em sua análise, que o estado de bem-estar arcava com os custos marginais do capital pelo lucro e assumia o papel de garantir que a mão de obra deixada para trás se tornaria novamente empregável - um esforço pecuniário ao qual o capital se recusava a empreender sozinho. 0 principal exemplo de Bauman para essa desconstrução, a partir dos anos 1980, são os sistemas de previdência social, "difamados como sendo um sorvedouro do dinheiro dos contribuintes" (ibid., p. 52).

Embora o Brasil sustente ainda a previdência pública por repartição, o sistema sofreu, como mencionado, inúmeras transformações nas reformas de 1998 e 2003, entre outras 
mudanças pontuais, porém relevantes, ${ }^{8}$ na onda do domínio da finança sobre a produção. Essas alterações se impõem, no entender de Chesnais (2005), pela dinâmica do "capital portador de juros" na mundialização financeira da economia contemporânea a partir da década de 1970. Esse movimento caracteriza um modelo de capitalismo patrimonialista que tem como combustível os investidores institucionais, incluindo nessa categoria os fundos de pensão e de previdência por capitalização e os fundos mútuos. Rica literatura (Castel, 2012; Castells, 1999; Antunes, 2006 e 2008) relata o impacto dessa financeirização ${ }^{9}$ também no mundo do trabalho de forma tão eficaz a ponto de providenciar uma nova categoria: o precariado (Paugam, 2000; Standing, 2013). Em poucas palavras, aquele trabalhador sem garantias da seguridade social e mergulhado na imprevisibilidade e incerteza.

Se o capital financeiro é o agente para a dissolução dos alicerces do Estado previdenciário ou a regulação do mundo do trabalho, sua fração imobiliária atua para materializar esse processo patrimonialista no espaço urbano (Gottdiener, 1993 apud Véras, 2000, p. 107). É preciso lembrar que nessa fração imobiliária estão inclusos, quase invariavelmente, recursos de investidores institucionais, pois estes são financiadores de empreendimentos. ${ }^{10}$ Esse conluio endógeno é que realiza o "Estado do Mal-Estar Social" no século XXI nas chamadas cidades globais (Sassen,1998) ao agir para a construção de um ambiente propício ao fluxo do capital. Essa nova paisagem, tal como prevista desde o fim do século passado (Véras, 2000, p. 106), constitui-se de prédios luxuosos, condomínios fechados, shoppings que alimentam a insaciabilidade do capital imobiliário e produzem, em contrapartida, segregação, gentrificação, precarização, além de usurpar 0 direito à cidade daqueles que dependem da intermediação do Estado para acessar seus locais de trabalho, lazer ou moradia que, por força das novas formas espaciais urbanas, passam a ser cristalizados na concepção mental do espaço urbano como o longe.

Esse aspecto será mais bem explorado adiante. Por ora, é necessário abordar como a pós-modernidade forja a nova velhice assim permitindo uma análise em paralelo dos dois temas deste artigo, envelhecimento e urbanização.

\section{A construção de uma nova velhice}

A expansão do capital, depois dos anos 1970, além de produzir uma metamorfose no mundo do trabalho, no Estado do Bem-Estar e no espaço urbano, como resumido acima, simula uma nova representação para a existência humana. Quanto a gênero, por exemplo, o chefe de família perde o papel de male breadwinner, e a mulher amplia, numa intensidade inédita, sua participação no mercado de trabalho, provocando uma revolução na família, na taxa de fecundidade, e impondo "uma nova ordem social" (Esping-Andersen, 2009, p. 1). Muitas outras formas dessa reformulação poderiam ser mencionadas, mas, dentro do propósito aqui estabelecido, a que nos interessa é a velhice.

Ao mesmo tempo que auxilia o avanço tecnológico possibilitando à humanidade uma vida mais longa, o capital financeiro age para cobrar a fatura, exigindo, em contrapartida, também o prolongamento da vida laboral. Essa 
cobrança chega justificada por um discurso de que se vive mais e melhor, o que é verdadeiro, porém carregado de simbologias. Debert (1999, p. 20) fez o diagnóstico dessa reinvenção da velhice ao apontar a sua "reprivatização" como consequência da atuação do capital em áreas nunca antes mercantilizadas .

Até a primeira metade do século $X X$, a velhice era responsabilidade quase exclusiva da família, que estava estabelecida em um arranjo sustentável. Num período posterior, relata Debert, o Estado do Bem-Estar Social dividiu com as famílias o risco da velhice. Num terceiro período, sob pressão para reduzir seus gastos e atuar com responsabilidade fiscal, a fim de garantir uma suposta estabilidade econômica, 0 Estado transferiu ao cidadão as responsabilidades, se possível de maneira integral, ${ }^{11}$ de suas demandas e obrigações relativas à qualidade de vida e à reprodução da força de trabalho.

0 discurso do envelhecimento ativo, ${ }^{12}$ segundo Debert (ibid., 162), "transforma o direito de escolha num dever" de todo cidadão. No entanto, a liberdade de escolha que essas palavras supõem é distribuída igualmente entre a população, ao contrário dos recursos públicos e privados exigidos para o seu exercício (ibid., p. 230). ${ }^{13}$ Segundo Guillemard (2013, p. 17), o conceito do envelhecimento ativo foi estabelecido por uma retórica econômica ambiciosa que jamais encontrou ressonância em políticas públicas, com exceção "no limitado domínio do emprego para manutenção dos idosos no mercado de trabalho" sem conseguir construir uma "cultura da idade" de forma favorável.

É evidente que se deve levar em conta a heterogeneidade desse segmento populacional, sem aceitar pré-noções de obrigatoriedade de uma velhice paupérrima ou, ao contrário, um idoso "fonte de recursos sem fim" ou de "pura potência". Mas, ao assumir uma velhice saudável, sustentável e a longevidade possível como destino inexorável do ser humano do século XXI, a sociedade atribui ao indivíduo um domínio total sobre o seu ciclo de vida, sem a interferência do Estado e a despeito, que é o importante neste texto, do tipo de interação que mantém com o "ambiente construído" das cidades. 0 discurso de universalização de uma velhice saudável, sem necessidades, dispensa o Estado de suas atribuições mais básicas e exclui a velhice do leque de preocupações da sociedade (Debert, 1999, p. 191).

No espaço concreto, porém, o trabalhador idoso enfrenta uma existência, defende-se aqui, em três dimensões. A primeira, a do invisível em suas necessidades básicas. ${ }^{14}$

A segunda, a do visível-sujo, a ser eliminado da paisagem em nome do que Bauman denomina "sonho de pureza" (1998, p. 13). Nessa dimensão, o idoso é visto como um estranho pelas "pessoas do lugar" Ele vai ocupar espaços privilegiados na fila do banco, por exemplo, no estacionamento do shopping, no transporte público, portanto, é visto como um estranho a quebrar a harmonia do ambiente. Ele é, de acordo com o raciocínio do autor, um "consumidor falho". Defende-se aqui que ele só deixa essa dimensão quando tem renda para "participar do jogo consumista" (ibid., p. 24).

A terceira dimensão é a do visível-limpo, na qual o idoso consegue manter sua força de trabalho e seu potencial de consumo. São os chamados seniores ou os tratados com o eufemismo de "terceira idade". Manter-se nessa última condição é a única estratégia para o idoso escapar do "autismo social" (Ianni,1994, p. 36) 
ou do ar blasé (Simmel, 1979, p. 18), atitudes típicas do ser da metrópole.

No discurso da economia mainstream, porém, existe apenas essa terceira dimensão. 0 idoso, portanto, de forma linear, como pessoa bem envelhecida e saudável - porque afinal dispôs de toda sorte de ferramentas para alcançar o estágio do envelhecimento ativo -, estaria apto a ampliar sua vida laboral e, assim, cooperar com a sustentabilidade dos sistemas de previdência que, agora, no século $X X I$, são raramente públicos de forma integral. A maioria deles é mista, sendo cada vez maior a parcela dos contribuintes filiada apenas aos sistemas privados. Como alerta Debert (1999), todavia, essa situação de conto de fadas está distante de ser uma opção. Se não o é para países onde predominou o amplo Estado do Bem-Estar Social no pós-guerra, é menos ainda para um País com a desigualdade social do Brasil, onde $63,7 \%$ dos idosos são chefes de família, $51,9 \%$ têm renda abaixo de um salário mínimo e escolaridade média de 3,9 anos de estudo (IBGE, 2011).

Esses dados, embora confirmem uma extensão da fase produtiva, embaçam a imagem dessa velhice que o discurso mainstream assume, realidade única e como capaz de protelar a decisão de passar à aposentadoria formal e de fato. Os números pouco revelam sobre as condições de inserção do idoso no mercado de trabalho e, menos ainda, explicam o impacto do espaço urbano nessa suposta escolha de postergar o fim da fase laboral. No empenho de tornar essa relação social menos abstrata, é preciso analisar melhor as cidades a partir desse ponto de vista. Em outras palavras, o quanto a cidade interfere na condição de trabalho do idoso, sobretudo no que diz respeito à mobilidade urbana, o que será feito na próxima seção.

\section{A construção do ambiente pelo capital}

As cidades são atores sociais complexos e assim se expressam na medida em que articulam e interagem com administrações públicas, agentes econômicos públicos e privados, organizações sociais e cívicas, setores intelectuais e profissionais, meios de comunicação e 0 próprio cidadão, ou seja, instituições políticas e sociedade civil (Borja e Castells, 1996, p. 152). A partir da crise econômica da década de 1970, as cidades, primeiro as europeias, foram empurradas para o papel de motores do desenvolvimento econômico. Nascia o conceito das Eurocidades. 0 mesmo ocorreu na Ásia (Seul, Taipei, Hong-Kong, Cingapura, Bancoque, Shanghai, entre outras) e, como citado acima, logo se tornou tendência mundial.

No mundo da economia global, destacam Borja e Castells, a velocidade da informação sobre os mercados internacionais, flexibilidade das estruturas produtivas e comerciais determinam o sucesso ou o fracasso. No "sistema cidade", os tecidos urbano e econômico se confundem sem, no entanto, conseguir evitar "altos custos sociais". Estes, porém, são insuportáveis a longo prazo, pois sua persistência implica fatores de dissuasão para a atratividade da cidade e não qualifica suficientemente os recursos humanos (1996, p. 153). De acordo com os autores, um plano estratégico de cidade seria inevitável para atender a demandas heterogêneas, a partir de um consenso social para refazer sistemas de convivência. 
Nas últimas décadas, porém, essas possibilidades se constituem cada vez mais improváveis. A sensação de crise funcional das grandes cidades tem se ampliado no século XXI, com a imposição da lógica da "cidade global" (Sassen, 1998), na qual prevalece a tendência dos agentes públicos de darem prioridade aos fluxos favoráveis às necessidades do capital na era da mundialização. Essa atitude promove uma metamorfose das grandes cidades em espaços construídos para facilitar o funcionamento dos sistemas econômicos transnacionais desregulamentados, financeirizados e sempre carentes de mais urgência em sua atuação em tempo real. A imagem das "elites voadoras" de Bauman (2003, p. 102) resume essa realidade. Essa cidade é forjada para o comportamento individualizado, em busca da segurança, com a ilusão de pertencimento ou, para usar a palavra predileta desse autor, um pertencimento líquido à comunidade.

Como esse diagnóstico se aplica à realidade brasileira e interfere nos temas centrais deste artigo? Seria possível incluir aqui literatura teórica para destacar o poder que tem esse movimento do capital no espaço urbano em usurpar o direito à cidade, como Kowarick (2000 e 2002), Harvey (1982, 2012 e 2014), Castells (1981) e Lefebvre (1991). No entanto, abre-se mão do enfoque teórico em benefício da exposição do atual estágio das cidades brasileiras, privilegiando-se, assim, o debate contemporâneo sobre a exclusão territorial. Em análise sobre a precariedade das cidades quanto à condição de domicílio, Rolnik e Klink (2011) destacam que, a despeito do avanço institucional da Constituição de 1988 quanto à função social da propriedade (artigo $5^{\circ}$, inciso XXIII) ${ }^{15}$ e do aumento "espetacular" do gasto público no desenvolvimento urbano entre os anos de 1999 e 2008, a desigualdade intraurbana resiste em virtude da reestruturação sociorreprodutiva e territorial do capital, verificada desde o fim dos anos 1970.

De acordo com o Relatório das Cidades no período 2002-2006, analisado pelos autores, persiste no Brasil a centralidade Sul-Sudeste e, quanto à possibilidade de desenvolvimento dos municípios, aparece, de forma crônica, a dependência da variável localização no território nacional. Esse diagnóstico é replicado na configuração intraurbana. 0 estudo, a partir de projeções com base na Pesquisa Nacional por Amostra de Domicílios (IBGE) para o ano 2010, constatou que apenas 33\% dos domicílios brasileiros eram totalmente adequados, em 30,5 milhões de moradias havia alguma inadequação e nenhum município apresentava $100 \%$ de seus domicílios plenamente adequados (p. 95). Na pesquisa, foram considerados adequados os domicílios com infraestrutura básica, abastecimento de água, saneamento, luz elétrica, localização, coleta de lixo e densidade populacional da moradia.

Os autores destacam que o dinamismo dos circuitos econômicos foi incapaz de produzir cidades com urbanidade e lembram que Oliveira (2003, p. 78), em sua crítica à razão dualista cepalina, que afirma que um segmento atrasado dificulta o avanço social, já ressaltava que esse mesmo imbricamento entre 0 atraso e o moderno é encontrado nas cidades brasileiras. De acordo com o autor, mesmo entre 1945-1980, o nível do salário real nas cidades se descolou do ritmo de crescimento econômi$\mathrm{Co}^{16}$ deixando o trabalhador com renda abaixo da necessária para a reprodução da força de trabalho urbana. 
Ao analisarem a evolução da massa salarial por empregado e o crescimento do PIB per capita nas cidades mais dinâmicas do País, no período 2002-2006, Rolnik e Klink concluem por uma provável distribuição funcional da renda, ou seja, aquela entre salários, lucro e renda da terra, em favor do capital e em prejuízo do trabalho, logo,

[...] na ausência de mecanismos compensatórios, o dinamismo econômico e a distribuição funcional de renda distorcida compõem um coquetel perverso, tendendo a agravar a situação do trabalhador pela exclusão socioespacial, alimentada pela valorização especulativa da terra. (2011, p. 101)

Antes de prosseguir com a avaliação de outra questão fundamental, a mobilidade urbana, é preciso destacar que, segundo Rolnik e Klink, ${ }^{17}$ a intervenção do Estado por meio de financiamentos, ampliação de crédito e especificamente o Programa de Aceleração do Crescimento (PAC), nos últimos 7 anos, apenas ampliou as consequências de fragmentação do território urbano. Ou seja, o caminho assumido pelo poder público é o oposto ao "plano estratégico" de cidade defendido por Borja e Castells, como citado acima. Como nos ensinam Véras (2000) e Campos Filho (1989), há várias visões conflitantes sobre a construção sociológica da cidade e o que vem a ser planejamento urbano. Seja qual for a visão, uma construção democrática e inclusiva depende de um processo "participativo", de novo segundo Borja e Castells, para haver chance de atingir o consenso social.

Um dos instrumentos para tal seria 0 chamado "plano diretor", ferramenta de participação popular instituída pela Constituição de
1988 e obrigatória para cidades com mais de 20 mil habitantes (art. 182, $\S 1^{\circ}$ ). No entanto, como sentencia Villaça (2000), expressões como "crescimento anárquico, caótico ou desordenado", que acompanham a ideia de "plano diretor", alimentaram um "mito" de que esse instrumento possa realmente configurar-se em uma solução para a questão urbana. Em sua visão, o "anárquico" e o "excludente" são resultados de uma vontade política de investimentos e escolhas quanto à ocupação do solo, independentemente de plano. Se o fosse, questiona, por que os bairros de alta renda cresceriam de forma ordenada e os de baixa renda de forma desordenada? 0 planejamento urbano, conclui, é usado de maneira ideológica, com a contribuição da imprensa, mais para esconder do que para resolver os problemas urbanos na contemporaneidade. ${ }^{18}$

Isto significa dizer que, em suas várias possibilidades de intervenção, por meio de programas de obras, crédito, financiamento ou plano diretor, o Estado, a depender dos compromissos de gestão, comparece muito mais como um fator de desintegração do que de integração. Ou melhor, de divergência do que de convergência, por mais que visões como a de Villaça possam ser relativizadas, pois a execução de um plano diretor atende a inúmeros interesses e lobbies, mas alguma coisa sempre sobra para o eleitor. Ao longo das últimas décadas, o ambiente tem sido construído majoritariamente pelo interesse do capital imobiliário (Rolnik, 2015) e com o Estado, quase sempre, à frente e possibilitando intervenções do mercado, o que produz maior segregação e desigualdade. É o caso de outro ponto caro ao objetivo deste texto: a mobilidade urbana. 
Villaça (2011) expõe ainda a importância do controle do tempo de deslocamento para a produção do espaço das cidades. Os homens, lembra ele, atuam sobre o espaço como meio de atuar sobre o tempo. 0 tempo de deslocamento, como consequência da segregação no ambiente da metrópole, reflete a desigualdade socioeconômica e, sobretudo, concentra os empregos (principalmente do setor terciário, mas também no secundário) cada vez mais distantes do local de residência dos pobres e, viciosamente, próximos daqueles habitantes "mais ricos", segundo o autor, e, portanto, com maior musculatura financeira para enfrentar a especulação imobiliária em seus bairros de residência. A classe dominante, conclui ele, manipula a produção desse espaço priorizando sempre a otimização dos seus tempos de deslocamento (p. 53), assim

[...] a temporalidade se faz presente nas sociedades que precisam sempre produzir mais e nas quais o trabalho de cada um, heterogêneo, qualitativo, transforma-se em quantidade de tempo [...] um continuum rígido. Essa temporalidade, pois, domina o sujeito: 0 tempo se transforma em espaço [...] Essas reflexões tomam o caráter abstrato da quantidade de tempo: no mundo espacializado do trabalho, 0 homem, indivíduo pessoal, afetivo, pouco importa [...]_só a engrenagem produtiva é relevante. (Véras, 2001, p. 7)

Embora os dados oficiais registrem um tempo médio de deslocamento casa-trabaIho (somente ida) da maioria da população $(66,9 \%)$ de até 30 minutos (Ipea, 2014), como mostrado no Gráfico 1, o segmento mais pobre das grandes cidades, moradores dos chamados subúrbios ou periferias, desperdiça o dobro ou o triplo desse tempo. ${ }^{19}$ Com o baixo investimento público nos sistemas de transporte ao longo das últimas décadas, os tempos de viagem casa-trabalho nas regiões metropolitanas triplicaram, e houve um crescimento da motorização individual, com destaque para a compra de motocicletas pela parcela de baixa renda da população, ${ }^{20}$ e da degradação dos meios coletivos que se tornaram, inclusive, áreas de insegurança e risco, principalmente para mulheres vítimas de abuso sexual.

Esse espaço de risco é intensificado ainda mais com a resposta do Estado às demandas de melhoria da mobilidade. Essa resposta foi antecipada, de forma profética, cabe aqui registrar, por vários autores ao longo da última década. Para Castel (2012),
a anomia suscita a violência [e acaba] desembocando não em uma "Grande Noi- te", mas em numerosas noites violentas, [e][...] uma sociedade democrática esta- ria, então, completamente desprovida, ou completamente desonrada diante da exi- gência de enfrentar essas desordens. Não comportam, com efeito, nenhuma outra resposta possível senão a repressão ou 0 fechamento em guetos. (p. 568)

Para Chesnais (2005), a concentração de riqueza provocada pela finança dominante, que interfere em todas as áreas, colocaria a sociedade

diante de uma situação propícia à acentuação do militarismo, assim como ao reforço dos métodos militares e de segurança para o controle político e social, tanto no plano internacional quanto no doméstico. (p. 57) 
Gráfico 1 - Tempo gasto no deslocamento casa-trabalho (somente ida)

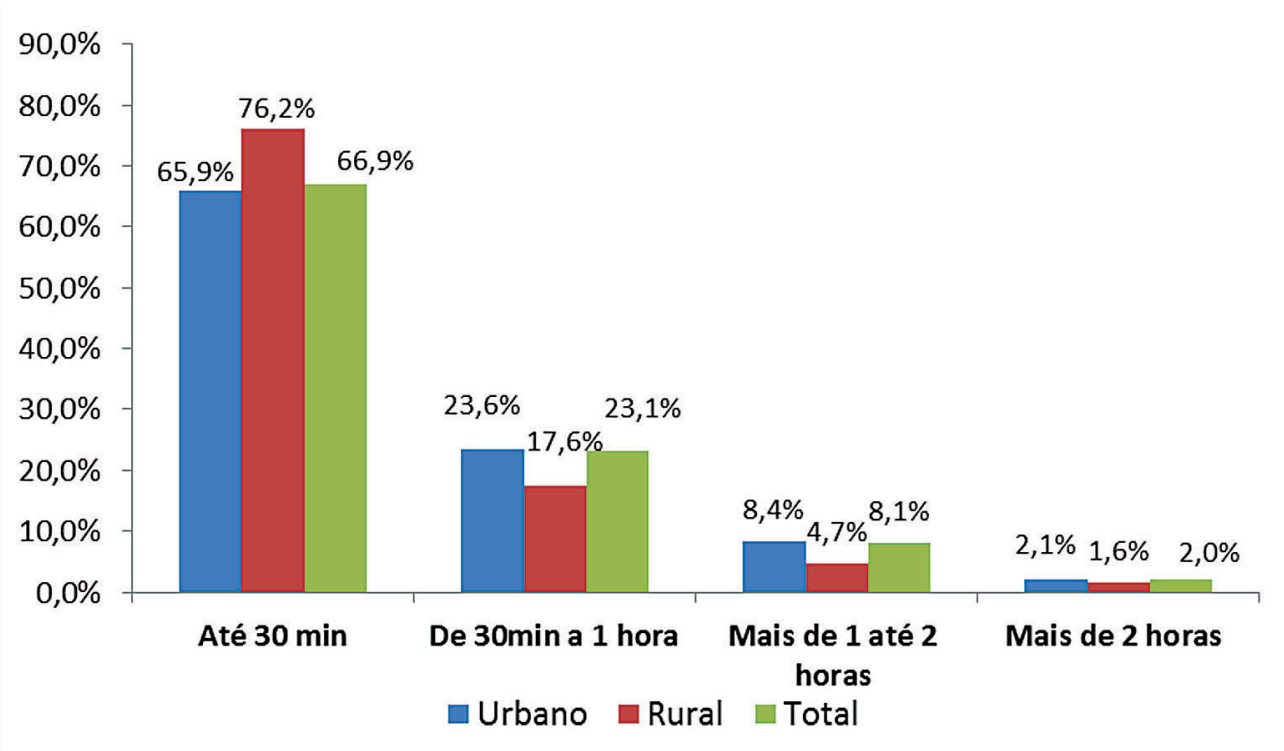

Fonte: Elaboração própria, a partir de Ipea (2013), com microdados da Pnad (2009).

Bauman (1998) já havia constatado que

o "problema" dos pobres fora remodelado como a questão da lei e da ordem, e os fundos sociais outrora destinados à recuperação de pessoas temporariamente desempregadas (em termos econômicos, a reacomodação da mão de obra) são despejados na construção e modernização tecnológica das prisões ou outros equipamentos punitivos e de vigilância. (p. 78)

0 propósito das citações foi registrar os alertas para a militarização da questão social e da gestão urbana como consequência da financeirização. Como constatado por Castells (2013), as manifestações que varreram o mundo no início deste século foram alimentadas pela resposta violenta desproporcional do
Estado aos protestos, como tentativa de impor a legitimidade perdida com o exercício do monopólio da violência. De acordo com o autor, vários foram os motivos para os protestos pelo mundo desde 2010 na Tunísia, mas a questão urbana estava subjacente a quase todos - sobretudo no Brasil.

Ao usarem a internet, razão de ser da denominada sociedade informacional, os manifestantes, na interpretação de Castells, buscaram se organizar para ocupar um espaço que consideravam ilegitimamente ocupado pelas autoridades, governos e empresas, vistos como responsáveis pela produção de "contradições entre uma democracia baseada no cidadão e uma cidade à venda pelo lance mais alto" (ibid., p. 177). A despeito de esses movimentos levantarem várias bandeiras, 
insinuando uma união frágil, Castells alerta para o fato de a mobilização ser permanente, por meio da rede virtual, e a qualquer momento se materializar no espaço físico. Essas cobranças por ocupar, portanto, resultam em ambiente de constante tensão nas cidades, nos bairros nevrálgicos, nas avenidas principais, no transporte público ou na periferia. Viver na cidade passa a ser a convivência com um estágio de violência perene e muito além do risco tradicional de assaltos.

Analisando o segmento idoso no cenário da cidade, em seus fluxos e velocidade, Guedes (2014), ao pesquisar as atitudes para com o idoso no Metrô de São Paulo, relatou como este se insere nas redes e itinerários, quais as representações sobre ele, como é percebido e tratado pelos demais usuários do Metrô. A sua questão central era apreender a produção da alteridade, ou seja, perceber como as pessoas concebem algumas como semelhantes, como um nós, parte do mesmo grupo social, ou porque outras são excluídas, tratadas como diferentes e categorizadas como eles. 0 autor coletou depoimentos que identificam as dificuldades no cotidiano das viagens pendulares casa e trabalho: "falta de respeito... convivência mais conflituosa que construtiva... reações de intolerância e discriminação":

Eu acho que em horários de pico os lugares preferenciais deveriam ser liberados! Pois a gente sai cansado do serviço e tem de dar lugar para os idosos que se prevalecem da idade e muitas vezes estão vindo de passear porque não tem nada para fazer em casa. (Apud Guedes, 2014, p. 78)

Em sua empreitada de manter-se na terceira dimensão da velhice, a visível-limpa, o trabalhador idoso é obrigado a adaptar-se a esse ambiente (re)construído. Ele habita, compartilha e frequenta diariamente o espaço público para exercer seu direito ao trabalho ou para atender a essa nova requisição do Estado, cada vez mais propício a enxergar o envelhecimento da população com lentes puramente fiscalistas, de protelar sua aposentadoria formal, estender sua vida laboral ou reinventar-se como nova força de trabalho depois do marco cronológico dos 60 anos. Em outras palavras, 0 desmonte do bem-estar social faz desaparecer aquela seguridade coletiva do passado e alcança um último estágio ao negar-lhe o direito à cidade.

\section{Considerações finais}

Em muitas análises sobre a velhice, o idoso é abordado quase como um ser à parte, uma autonomização da existência humana, sem ciclo de vida. Neste texto, ao analisar a cidade como um "ambiente construído", procurou-se mostrar que a questão urbana interfere na construção das possibilidades da velhice. Se vive na cidade, logo, assim como todos os outros fatores relacionados com a determinação do bem-estar na fase idosa, como alimentação, exercício físico, educação, vícios, prevenção, o meio urbano também influencia as condições do envelhecimento. 0 objetivo aqui foi questionar, especificamente, qual o papel do espaço urbano na decisão individual de prolongar a vida laboral ou para o trabalhador escolher o momento da aposentadoria formal.

Foi analisado o papel do capital financeiro no desmonte do Estado do Bem-Estar 
Social, sobretudo a partir dos anos 1970 e, principalmente, depois de 1990 e nos dias atuais, dominados pelos efeitos da crise mundial deflagrada em 2007-2008. Foi visto como a dinâmica da financeirização promove uma metamorfose na representação da velhice, tomando como universais as possibilidades do envelhecimento ativo. 0 capital financeiro, como agente do desmonte do Estado do Bem-Estar, atua - em sua fração capital imobiliário para forjar a cidade como "ambiente construído" e, portanto, reduzindo as oportunidades de bem-estar durante todo o ciclo de vida do trabalhador urbano, limitando, assim, suas possibilidades na velhice.

A hipótese suscitada pela pesquisa bibliográfica, mesmo que seja explorada em ocasiões posteriores, é que a degradação da vida urbana, a segregação e a exclusão, provocadas pelo predomínio dos interesses do capital imobiliário, são fatores que contribuem para a antecipação da aposentadoria formal. A situação das cidades penaliza ainda mais o usuário vulnerável do transporte coletivo e/ou o morador de menor renda. No caso do trabalhador idoso, ele é obrigado a se submeter a toda sorte de risco no espaço público sem chance de escolhas, logo, opta por livrar-se tão logo seja possível dessa condição. Registra-se que a idade média de aposentadoria no Brasil é de 54 anos - um ano a mais do que era em 1998, data da primeira reforma da Previdência Social, que instituiu o fator previdenciário (Camarano et al., 2012).

0 aumento dos custos sobre moradia e transporte, principalmente, mas também lazer, saúde e outras despesas, antes divididas com o Estado e hoje mercantilizadas, estariam empurrando o trabalhador para a aposentadoria considerada precoce pelos parâmetros que 0 próprio Estado, pressionado pelas exigências do capital, procura estabelecer como regra de idade mínima. Ainda que permaneça, no mercado de trabalho na condição de aposentado, o trabalhador maduro opta pela aposentadoria para abrir alternativas de sobrevivência, influenciadas pela degradação das cidades, como reduzir seu tempo de mobilidade com a obtenção de um emprego mais próximo de seu local de residência - na maioria das vezes em condição informal - ou buscar empregabilidade em cidades menores.

Mesmo com o valor de seu benefício reduzido, ao incidir o fator previdenciário sobre 0 cálculo, o trabalhador opta pela aposentadoria considerada precoce. Um dos fatores determinantes de sua decisão seria "se livrar" da agrura de ida e vinda diária ao local de trabalho na grande cidade. Seu benefício reduzido, então, passa a ser uma complementação da renda vislumbrada pela permanência no mercado de trabalho em situação informal, no caso dos menos qualificados, como afirmam Camarano et al. (ibid.). Uma das hipóteses para essa renda é ajudar a sustentar os custos crescentes de morar na cidade (média ou grande), onde as condições de se reinventar na velhice podem ser mais promissoras.

Vale destacar ainda o duplo papel do capital financeiro a produzir um discurso e uma ação paradoxal sobre o sistema de aposentadorias. De um lado, o capital atua para construir um ambiente urbano a favor de sua reprodução e acumulação em detrimento do bem-estar do trabalhador. De outro, sob a justificativa da existência de um novo enveIhecer ou do envelhecimento populacional, exige a protelação da aposentadoria em favor 
do equilíbrio fiscal ou mesmo vislumbra retirar do Estado a responsabilidade previdenciária. No entanto, as duas atuações entram em confronto na prática e resultam no efeito contrário, ou seja, um estímulo adicional à antecipação da aposentadoria.

\section{Maura Pardini Bicudo Véras}

Pontifícia Universidade Católica de São Paulo, Faculdade de Sociologia, Departamento de Ciências Sociais. São Paulo, SP/Brasil.

mauraveras9@gmail.com

\section{Jorge Felix}

Universidade de São Paulo, Fundação Escola de Sociologia e Política de São Paulo. São Paulo, SP/ Brasil

jorgemarfelix@gmail.com

\section{Notas}

(1) Os termos "globalização" e "mundialização" são, muitas vezes, usados como equivalentes, porém são falsos sinônimos. O primeiro tem origem nas escolas de administração de empresas norte-americanas, e o segundo é de formulação de economistas franceses (mondialisation). Os que cunharam o primeiro concebem o mundo contemporâneo como um globo plano e assumem que todos os agentes econômicos dispõem de iguais oportunidades de competição; os que usam o segundo entendem que o mundo é um espaço hierarquizado, cujas regras são as que mais convêm às potências capitalistas centrais. Ver Chesnais (1996, p. 24) e Stiglitz (2007, p. 411).

(2) Optou-se aqui por usar os dados do Censo. No entanto, na Síntese dos Indicadores Sociais do IBGE, a expectativa de vida do brasileiro ao nascer, em 2014, era de 75,1 anos contra 74,9, em 2013, e 74,6 em 2012 (IBGE, 2015).

(3) No caso do Brasil, Seguridade Social, como delimita o Artigo 194 da Constituição Federal, isto é, saúde universal, previdência social e assistência social.

(4) Ver Esping-Andersen (2008), Palier (2003), para o contexto internacional, e Felix (2012), para o nacional.

(5) Estabelece-se como definição de idoso e "trabalhador idoso" a pessoa com mais de 60 anos de idade, como determinam o marco legal brasileiro e a Organização das Nações Unidas. Nos países ricos, a ONU estabelece a idade de 65 anos para considerar a pessoa idosa. 
(6) O discurso econômico mainstream é entendido, aqui, como a narrativa sobre a política econômica que se tornou hegemônica na mídia internacional e nos organismos multilaterais, como Banco Mundial, Organização Mundial do Comércio, Fundo Monetário Internacional, a partir do fim dos anos 1980 quando este último adotou um receituário com dez recomendações econômicas, conhecido como Consenso de Washington, para todos os países da América Latina. Essas ideias, porém, também foram empreendidas na economia europeia promovendo a desconstrução do Estado do Bem-Estar Social do pós- Segunda Guerra Mundial. Essa "receita única" para esses países alcançarem o equilíbrio macroeconômico previa austeridade fiscal, redução da carga tributária, câmbio flutuante, "juros de mercado", abertura comercial, eliminação de restrições ao Investimento Estrangeiro Direto, desregulamentação financeira, direito à propriedade intelectual (patentes) e privatização das estatais e dos sistemas de previdência social. Esse discurso domina o ambiente entre 1978 até a crise financeira de 2008, período batizado de “Trinta Anos Neoliberais" (Bresser-Pereira, 2015, p. 17).

(7) Ver Esping-Andersen (2008) ou quadro esquemático em Guillemard (2010, p. 106).

(8) Ver detalhes em Batich (2010) e Felix (2012).

(9) Ver Chesnais (2005).

(10) A empresa PDG, por exemplo, líder do setor imobiliário da América Latina, tem a seguinte composição acionária: 15,74\% Orbis Investment Management Ltd; 10,53\% Vinci Equities Gestora de Recursos Ltd; 9,13\% Vinci Capital Partners II Fundo de Investimento em Participações; 5,39\% Platinum Investment Management Ltd; 5,31\% Bank of America; 5,15\% Skopos Investment Ltd; 0,51\% diretoria; e 48,24\% Outros, de acordo com informações do site da empresa acessado em 24 de outubro de 2014:. http://ri.pdg.com.br/conteudo_pt.asp?idioma=0\&conta=28\&ti po=32510. Acessado em: 24 out 2014.

(11) Cita-se aqui, a título de ilustração, o exemplo do Chile, que privatizou totalmente a previdência e, parcialmente, a saúde e a educação.

(12) Ver OMS (2002).

(13) Sobre escolhas, do ponto de vista da Economia Social, ver Sen (1999, pp. 141-142). Vale a citação de Bauman (1998, p. 118): "A liberdade de escolha, eu lhes digo, é de longe, na sociedade pós-moderna, o mais essencial entre os fatores de estratificação".

(14) Ver Berzins e Borges (2012); Camarano (2010) e Hirata e Guimarães (2012).

(15) Os autores citam ainda os artigos 182 e 183 da CF (capítulo Política Urbana) e o Estatuto da Cidade (Lei Federal 11.257/2001).

(16) Ver Pochmann (2007), para obter dados sobre o poder de compra do salário mínimo no período (p. 118) e em relação à renda nacional (p. 122).

(17) Para sustentar a afirmação, os autores citam Leitão (2009).

(18) Outras críticas ao planejamento urbano são feitas por Sennett (1988), ao tratar das tiranias da intimidade e do esvaziamento dos espaços públicos, pois o planejador, ao tentar oferecer praças, melhorar a qualidade de vida, não consegue ler as enfermidades sociais e acaba por encontrar nos munícipes desconfiança em relação aos outros ou uma perversão do que entendem por vida comunitária "[...]cria a própria esterilidade que poderia estar querendo evitar" (p. 380). 
(19) É importante destacar que esse percentual se refere a toda área urbana do país, metropolitana ou não. Até 1 h são 23,6\%, enquanto 8,4\% demoram de 1 a 2 horas e 2,1\% mais de 2 horas.

(20) Mais da metade (54\%) dos domicílios brasileiros têm um automóvel ou motocicleta. De 2008 para 2012, o percentual de domicílios com esses tipos de veículos subiu nove pontos percentuais (45\% em 2008 para 54\% em 2012). As motocicletas tiveram o maior incremento, e os acidentes são responsáveis por 12 mil mortes por ano. No estrato de renda de até um quarto do salário mínimo per capita, $28 \%$ das famílias possuem carro ou moto, e nessa população há maior ocorrência de posse de motocicleta. De 2008 a 2012, a posse de veículos privados na camada mais pobre subiu 10 pontos percentuais. Das famílias abaixo da linha da pobreza (até meio salário mínimo per capita), 35\% já usufruem de veículos privados, 12 pontos percentuais acima do índice de 2008 (Ipea, 2013, p. 3).

\section{Referências}

ANTUNES, R. (2006). Riqueza e miséria do trabalho no Brasil. São Paulo, Boitempo.

(2008). O caracol e sua concha: ensaios sobre a nova morfologia do trabalho. São Paulo, Boitempo.

(2011). Adeus trabalho?: ensaio sobre as metamorfoses e a centralidade do mundo do trabalho. São Paulo, Cortez.

BATICH, M. (2010). “A previdência social sob a mira dos fundos de pensão". In: MARQUES, R. M. e FERREIRA, M. R. J. (orgs.). O Brasil sob a nova ordem, a economia brasileira contemporânea, uma análise dos governos Collor a Lula. São Paulo, Saraiva.

BAUMAN, Z. (1998). O mal-estar da pós-modernidade. Rio de Janeiro, Zahar.

(2003). Comunidade, a busca por segurança no mundo atual. Rio de Janeiro, Zahar.

BERZINS, M. V. e BORGES, M. C. (2012). Políticas públicas para um país que envelhece. São Paulo, Martinari.

BORJA, J. e CASTELLS, M. (1996). As cidades como atores políticos. Revista Novos Estudos. São Paulo, Cebrap, n. 45.

BRESSER-PEREIRA, L. C. (2015). A construção política do Brasil, sociedade, economia e Estado desde a Independência. São Paulo, Editora 34

CAMARANO, A. A.; KANSO, S. e FERNANDES, D. (2012). Saída do mercado de trabalho: qual é a idade? Mercado de Trabalho. Rio de Janeiro, Ipea, v. 1, pp. 19-28.

CAMARANO, A. A. (org.) (2010). Cuidados de longa duração para a população idosa, um novo risco social a ser assumido? Rio de Janeiro, Ipea.

CAMPOS FILHO, C. M. (1989). Cidades brasileiras: seu controle ou o caos. São Paulo, Nobel.

CASTEL, R. (2012). As metamorfoses da questão social, uma crônica do salário. Petrópolis/RJ, Vozes. 
CASTELLS, M. (1981) A questão urbana. São Paulo, Paz \& Terra

(1999). A sociedade em rede. A era da informação: economia, sociedade e cultura. São Paulo, Paz \& Terra.

(2013). Redes de indignação e esperança. Rio de Janeiro, Zahar.

CHESNAIS, F. (1996). A mundialização do capital. São Paulo, Xamã.

(2005). A finança mundializada. São Paulo, Boitempo.

CONSTITUIÇÃO DA REPÚBLICA FEDERATIVA DO BRASIL (1991). São Paulo, Saraiva.

DEBERT, G. G. (1999). A reinvenção da velhice: socialização e processos de reprivatização do envelhecimento. São Paulo, Edusp/Fapesp.

ESPING-ANDERSEN, G. (2008). Trois leçons sur l'État-providence. Paris, Seuil.

(2009). The incomplete revolution, adapting to women's new roles. Cambridge, Polity Press.

FELIX, J. (2012). "Desafios da previdência social para um país que envelhece e o risco da aposentadoria como prêmio". In: BERZINS, M. V. e BORGES, M. C. (orgs.). Políticas públicas para um país que envelhece. São Paulo, Martinari.

GUEDES, C. E. F. (2014). Alteridade e cidadania: os idosos usuários do Metrô de São Paulo. Tese de Doutorado. São Paulo, Pontifícia Universidade Católica de São Paulo.

GUILLEMARD, A. M. (2010). Le défis du vieillissement-âge, employ, retraite: perspective international. Paris, Armand Colin.

(2013). Le vieillissement actif: enjeux, obstacles, limites - une perspective internationale. Retraite et Société. Paris, n. 65, pp. 17-38.

HARVEY, D. (1982). O trabalho, o capital e o conflito de classes em torno do ambiente construído nas sociedades capitalistas avançadas. Revista Espaço e Debates, n. 6.

(2012). Il capitalismo contro il diritto alla città. Verona, Ombre Corte.

(2014). Cidades rebeldes - do direito à cidade à revolução urbana. São Paulo, Martins Fontes/ Selo Martins.

HIRATA, H. e GUIMARÃES, N. (orgs.) (2012). Cuidado e cuidadoras - as várias faces do trabalho do care. Rio de Janeiro, Atlas.

IANNI, O. (1994). A cidade global. Revista Cultura Vozes. São Paulo, ano 88, v. LXXXVIII, n. 2.

IBGE (2011). Censo Demográfico 2010, site do Instituto Brasileiro de Geografia e Estatística, Rio de Janeiro. Disponível em: http://www.ibge.gov.br/home/estatistica/populacao/censo2010/. Acesso em: 6 set 2015 .

(2015). Síntese de indicadores sociais: uma análise das condições de vida da população brasileira. Rio de Janeiro, Coordenação de População e Indicadores Sociais.

IPEA (2014). Indicadores da mobilidade urbana da Pnad 2012. Comunicado n. 161. Rio de Janeiro, Ipea. JUDT, T. (2007). Pós-guerra, uma história da Europa desde 1945. Rio de Janeiro, Objetiva. 
KOWARICK, L. (2000). Escritos urbanos. São Paulo, Editora 34.

(2002). Viver em risco: sobre a vulnerabilidade no Brasil urbano. Novos Estudos. São Paulo, Cebrap, n. 61.

LEFEBVRE, H. (1991). O direito à cidade. São Paulo, Moraes.

LEITÃO, K. O. (2009). A dimensão territorial do Programa de Aceleração do Crescimento. Tese de Doutorado. São Paulo, Universidade de São Paulo.

OLIVEIRA, F. (2003). Crítica à razão dualista. O ornitorrinco. São Paulo, Boitempo.

(2004). Por que política? Palestra no Fórum da Sociedade Civil na Unctad, São Paulo. Disponível em: http://www.ibase.br/userimages/francisco_de_oliveira_port.pdf. Acesso em: 5 maio 2014.

OMS (2002). Envelhecimento ativo, uma política de saúde. Genebra. Publicação da Organização Mundial da Saúde. Disponível em: http://bvsms.saude.gov.br/bvs/publicacoes/envelhecimento_ ativo.pdf. Acesso em: 20 abr 2016.

(2008). Guia Global: Cidade Amiga do Idoso. Genebra, publicação da Organização Mundial da Saúde. Disponível em: http://www.who.int/ageing/GuiaAFCPortuguese.pdf. Acesso em: 20 abr 2016.

PALIER, B. (2003). La reforme des retraites, traivaller plus? Paris, Presses Universitaires de France.

PAUGAM, S. (2000). Le salarié de la précarité. Paris, Presses Universitaires de France.

POCHMANN, M. (2007). O emprego no desenvolvimento da nação. São Paulo, Boitempo.

ROLNIK, R. (2015). Guerra dos lugares, a colonização da terra e da moradia na era das finanças. São Paulo, Boitempo.

ROLNIK, R. e KLINK, J. (2011). Crescimento econômico e desenvolvimento urbano: por que as cidades continuam tão precárias? Revista Novos Estudos. São Paulo, Cebrap, n. 89.

SANTOS, M. (1987). O espaço do cidadão. São Paulo, Nobel.

SASSEN, S. (1998). As cidades na economia mundial. São Paulo, Nobel.

SEN, A. (1999). Desenvolvimento como liberdade. São Paulo, Companhia das Letras.

SENNETT, R. (1988). O declínio do homem público, as tiranias da intimidade. São Paulo, Companhia das Letras.

SIMMEL, G. (1979). “A metrópole e a vida mental”. In: VELHO, O. G. (org.). O fenômeno urbano. Rio de Janeiro, Zahar.

STANDING, G. (2013). O precariado, a nova classe perigosa. Belo Horizonte, Autêntica.

STIGLITZ, J. E. (2007). Globalização, como dar certo. São Paulo, Companhia das Letras.

VÉRAS, M. P. B. (2000). Trocando olhares: uma introdução à construção sociológica da cidade. São Paulo, Studio Nobel/Educ.

(2001). Tempo e espaço na metrópole. Revista São Paulo em Perspectiva. São Paulo, Fundação Seade, v. 15, n. 1. 
VILLAÇA, F. (2000). Perspectivas do planejamento urbano no Brasil de hoje. Texto apresentado no Congresso de Campo Grande (MS) (mimeo).

(2011). São Paulo, segregação urbana e desigualdade. Revista de Estudos Avançados. São Paulo, Edusp, n. 25.

Texto recebido em 12/set/2015

Texto aprovado em 25/fev/2016 
